\title{
Doppler measurements in fetal descending aorta and umbilical artery can predict borderline oxygenation in pre-eclampsia and HELLP syndrome
}

\author{
Susanne E. Gruessner ${ }^{1,2 *}$, Charles O. A. Omwandho ${ }^{3}$, Corinna Peter ${ }^{4}$ \\ ${ }^{1}$ Department of Obstetrics, Gynecology and Reproductive Medicine, Hannover Medical School, Hannover, Germany \\ ${ }^{2}$ Department of Obstetrics and Gynecology, Justus-Liebig-University of Giessen, Giessen, Germany \\ ${ }^{3}$ Department of Biochemistry, University of Nairobi, Nairobi, Kenya \\ ${ }^{4}$ Department of Pediatric Pulmonology, Allergology and Neonatology, Hannover Medical School, Hannover, Germany \\ Email: " gruessner.susanne@mh-hannover.de, ${ }^{*}$ susanne.gruessner@gmx.de
}

Received 27 July 2012; revised 31 August 2012; accepted 11 September 2012

\begin{abstract}
Objective: To determine diagnostic utility of Doppler measurements in fetal descending aorta and umbilical arteries in predicting intrauterine growth retarded (IUGR) fetuses at risk in pregnancies complicated by pre-eclampsia and/or HELLP syndrome. Methods: Doppler measurements were taken in fetal descending aorta and umbilical arteries of 53 patients with pre-eclampsia, 10 of whom had HELLP syndrome using fetometry (ACUSON 128XP/10, 3.5 MHz probe). These values were compared with those of 44 appropriate-for-gestational age singleton pregnancies (AGA). Doppler Indices (Resistance Index (RI), Systolic/Diastolic (S/D) ratio) and end-diastolic flows were related to fetal heart rate (FHR) during contraction stress test, to cord blood parameters (pH, Base Excess) and to Apgar Scores. Results: In contrast to AGA fetuses, IUGR fetuses had decreased end-diastolic flow and an increase of Doppler Indices significantly earlier in the descending aorta $(p<0.05)$, compared to umbilical artery. Increased RI's, S/D ratios and a decrease of end-diastolic flow in fetal aorta were significantly correlated to frequency of FHR decelerations during contraction stress tests, pH, Base Excess (p < 0.01) and Apgar Scores in IUGR fetuses. Conclusion: A decrease in end-diastolic flow paralleled with an increase in Doppler indices in fetal descending aorta reflect oxygen deprivation in IUGR fetuses during pre-eclamptic pregnancies with or without HELLP syndrome. While ductus venous and umbilical artery are more frequently used nowadays to determine fetal oxygen deprivation, Doppler measurements in fetal descending aorta provide additional information for early detection of fetuses at risk for IUGR in pregnan-
\end{abstract}

${ }^{*}$ Corresponding author. cies complicated with pre-eclampsia and/or HELLP syndrome.

Keywords: Pre-Eclampsia; IUGR; Doppler Velocimetry; Fetal Descending Aorta

\section{INTRODUCTION}

In pre-eclamptic pregnancies complicated with HELLP syndrome, a severe form of pre-eclampsia, the fetus is deprived of oxygen. Consequential there is redistribution of organ blood flow and an increase of resistance in fetal vessels leading to intrauterine growth retardation (IUGR) or fetal death [1]. Clinical diagnosis is difficult but usually associated with abdominal pain or vomiting during third trimester of pregnancy, hemolysis, increased serum bilirubin $(>1.2 \mathrm{mg} / \mathrm{dL})$, hepatic dysfunction demonstrated by increased transaminase activities (LDH $>600$ $\mathrm{IU} / \mathrm{L})$, and thrombocytopenia $(<100.000 / \mu 1)$ [2]. Prognosis is poorer when pre-eclampsia develops earlier in pregnancy [1]. Although the descending aortic blood flow represents approximately $60 \%$ of fetal cardiac output, cardiotocography, serial ultrasound measurements, and Doppler flow velocimetry of umbilical artery and fetal middle cerebral arteries have commonly been used to assess fetal well-being and to guide management of pregnancies complicated with pre-eclampsia with or without HELLP syndrome [3-8]. None of these studies have compared diagnostic utility of fetal descending aorta and/ or umbilical artery with late fetal heart rate (FHR) decelerations following a contraction stress test. The purpose of this study was to investigate 1) whether or not Doppler flow measurements of descending aorta and/or umbilical artery can sufficiently predict blood flow redistribution in growth retarded (IUGR) compared to appropriate for gestational age (AGA) fetuses, 2) if the decrease 
in end-diastolic-flow $\left(\mathrm{V}_{\min }\right)$ in descending aorta occurs parallel to late fetal heart rate decelerations during fetal stress, 3) correlation between Resistance Index (RI) and $\mathrm{S} / \mathrm{D}$ ratio of fetal descending aorta and/or umbilical artery with the decrease of stress test score (CTG) of FHR and 4) whether or not the RI of fetal descending aorta and/or umbilical artery correlates with birth weight, cord blood gas parameters $\left(\mathrm{pH}, \mathrm{pO}_{2}\right.$, Base excess) and Apgar Scores.

\section{MATERIALS AND METHODS}

The study population consisted of 53 patients, 43 of whom had pre-eclampsia and 10 with pre-eclampsia complicated with HELLP syndrome. The control group consisted of 44 patients with biometric data of AGA fetuses. Pre-eclampsia was defined by the triad of elevated maternal blood pressure (systolic blood pressure $>150$ $\mathrm{mmHg}$ and/or diastolic pressure $>90 \mathrm{mmHg}$ on 2 occasions, 6 hours apart), proteinuria ( $>300 \mathrm{mg}$ per 24 hours) and generalized maternal edema. HELLP syndrome was defined by hemolysis (bilirubin $>1.2 \mathrm{mg} / \mathrm{dl}$, hemorrhage, anemia, elevated liver enzymes (lactate dehydrogenase, $\mathrm{LDH}>600 \mathrm{U} / \mathrm{l}$, alanine aminotransferase, ALT $>$ $47 \mathrm{U} / \mathrm{l}$, aspartate aminotransferase, AST $>56 \mathrm{U} / \mathrm{l})$ and low platelet counts $(<100.000 / \mu 1)$.

A pulsed Doppler ACUSON $128 \mathrm{XP} / 10$ with a 3.5 $\mathrm{MHz}$ probe was used for fetometry. IUGR was based on assessment of birth weight $<10^{\text {th }}$ percentile for gestational age, according to percentile charts for singleton fetuses, developed by Hohenauer [9].

End-diastolic-flow velocity $\left(\mathrm{V}_{\min }\right)$ and Doppler indices (RI, S/D ratio) of fetal descending aorta and umbilical artery were related to fetal heart rate pattern during contraction stress test. In order to provide information on uterine reserve capacity and predict borderline oxygenation following fetal heart reactions, uterine contractions were either spontaneous or induced by inhalation or infusion of oxytocin in cases where contractions were not registered in pregnancies with IUGR fetuses. Only the last Doppler measurements within 0 - 5 days before birth were used for analysis. Fetal heart rate score (CTG score) was carried out by evaluating baseline frequency, oscillations and accelerations, long term alterations and decelerations. The score was related to uterine contractions with ten points best and zero points poorest result. Doppler spectral recordings were taken from placental insertion of umbilical artery and fetal descending aorta. Mothers were either in a supine position or at a slight left lateral tilt during these investigations. Maximum systolic $\left(\mathrm{V}_{\max }\right)$ and end-diastolic $\left(\mathrm{V}_{\min }\right)$ velocities were measured as frequencies $(\mathrm{Hz})$ using calipers to obtain three reproducible recorded waveforms. Patients with pre-eclampsia and/or HELLP syndrome were delivered by caesarean section, while the control group had vaginal delivery. For statistical analysis, correlation coefficient and linear regression models were calculated with a $\mathrm{p}$ value $<0.05$ indicating statistical significance. Qualitative variables were compared by Fisher's exact and Chi square tests while quantitative variables were compared using the Wilcoxon 2 sample test. Ethical clearance was obtained from the relevant office and experiments conducted in accordance with the Helsinki declaration of 1982 regarding use of human subjects.

\section{RESULTS}

Median gestational age was 32 weeks vs. 29 weeks for pre-eclamptic patients and those with HELLP syndrome respectively compared to 40 weeks in the control group (Table 1). The median end-diastolic velocity of fetal descending aorta was significantly decreased $(0 \mathrm{~Hz})$ in both study groups (Wilcoxon 2 sample test: $\mathrm{p}<0.0001$; $\mathrm{Chi}^{2}$ test: $\mathrm{p}<0.0001)$ compared to control group $(355 \mathrm{~Hz})$. End-diastolic velocity of umbilical artery was $175 \mathrm{~Hz}$ in the pre-eclamptic group, $0 \mathrm{~Hz}$ in HELLP, and $450 \mathrm{~Hz}$ in the control groups respectively (Table 1). Differences in end-diastolic flow velocity of umbilical artery were sig-

Table 1. Flow velocities vs. gestational age and birth weight.

\begin{tabular}{|c|c|c|c|c|c|c|}
\hline \multirow[b]{2}{*}{$\begin{array}{l}\text { Number of Patients } \\
\text { (n) }\end{array}$} & \multirow[b]{2}{*}{$\begin{array}{l}\text { Gestational Age [wk] } \\
\text { Median (min-max) }\end{array}$} & \multirow[b]{2}{*}{$\begin{array}{l}\text { Birth Weights }[\mathrm{g}] \\
\text { Median (min-max) }\end{array}$} & \multicolumn{2}{|c|}{ Fetal descending aorta } & \multicolumn{2}{|c|}{ Umbilical artery } \\
\hline & & & $\begin{array}{c}\mathrm{V}_{\max }[\mathrm{Hz}] \\
\text { Median (min-max) }\end{array}$ & $\begin{array}{c}\mathrm{V}_{\min }[\mathrm{Hz}] \\
\text { Median (min-max) }\end{array}$ & $\begin{array}{c}\mathrm{V}_{\max }[\mathrm{Hz}] \\
\text { Median (min-max) }\end{array}$ & $\begin{array}{c}\mathrm{V}_{\min }[\mathrm{Hz}] \\
\text { Median (min-max) }\end{array}$ \\
\hline Pre-Eclampsia (43) & $32(27-40)$ & $1130(510-2750)$ & $1200(675-1920)$ & $0(0-250)$ & $925(475-1770)$ & $175(0-440)$ \\
\hline HELLP (10) & $29(27-39)$ & $940(510-2500)$ & $1188(870-1850)$ & $0(0-200)$ & $925(600-1350)$ & $0(0-250)$ \\
\hline p HELLP vs. Control & $<0.0001$ & $<0.0001$ & 0.008 & $<0.0001$ & 0.16 & $<0.0001$ \\
\hline $\begin{array}{l}\text { p Pre-Eclampsia } \\
\text { vs. Control }\end{array}$ & $<0.0001$ & $<0.0001$ & 0.001 & $<0.0001$ & $<0.0001$ & $<0.0001$ \\
\hline $\begin{array}{c}\text { p HELLP } \\
\text { vs. Pre-Eclampsia }\end{array}$ & 0.132 & 0.24 & 0.546 & 0.615 & 0.633 & 0.055 \\
\hline
\end{tabular}


nificant for both study groups (Wilcoxon 2 sample test: $\mathrm{p}$ $=0.0001$; $\mathrm{Chi}^{2}$ test: $\left.\mathrm{p}=0.0001\right)$ compared to controls. End-diastolic flow velocity was significantly lower in the descending aorta for patients with HELLP syndrome $\left(\mathrm{R}_{\mathrm{p}}\right.$ $\left.=0.7, \mathrm{p}<0.0001, \mathrm{R}_{\text {HELLP }}=0.93, \mathrm{p}<0.0001\right)$ and in the control group $(\mathrm{Rc}=0.49, \mathrm{p}=0.001)$ compared to umbilical artery (Figure 1). The decrease in fetal heart rate score was paralleled with loss of end-diastolic flow velocity in the fetal descending aorta $\left(\mathrm{R}_{\mathrm{p}}=0.46, \mathrm{p}=0.002\right.$; $\mathrm{R}_{\text {HELLP }}=0.56, \mathrm{p}=0.092$ ) (Figure 2), rather than in the umbilical artery $\left(\mathrm{R}_{\mathrm{p}}=0.41, \mathrm{p}=0.006 ; \mathrm{R}_{\mathrm{HELLP}}=0.44, \mathrm{p}=\right.$ $0.20)$. CTG score was 4 points in pre-eclamptic patients; 3.5 in patients with HELLP syndrome compared to 10 points in controls. Differences between CTG scores of



Figure 1. End-diastolic flow velocities $\left(\mathrm{V}_{\mathrm{min}}\right)$ in fetal descending aorta vs. umbilical artery.

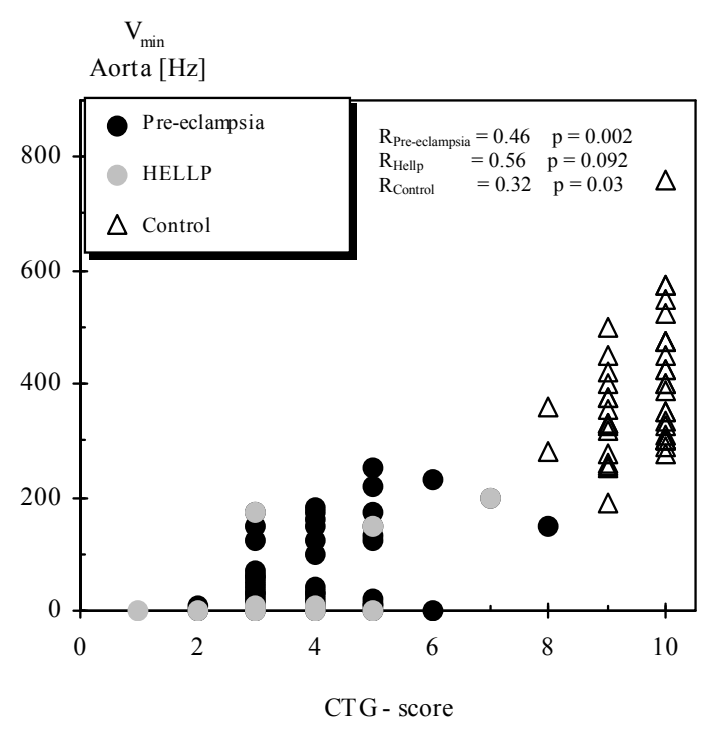

Figure 2. End-diastolic flow velocities $\left(\mathrm{V}_{\min }\right)$ in fetal descending aorta vs. CTG score. pre-eclamptic patients with HELLP syndrome was significant, compared to control group (Wilcoxon 2 sample test: $\mathrm{p}<0.0001$; Chi $^{2}$ test: $\left.\mathrm{p}<0.0001\right)$. Median birth weight was $3430 \mathrm{~g}$ for the control group, $1130 \mathrm{~g}$ in preeclamptic group and $940 \mathrm{~g}$ in HELLP syndrome group. An increase of $\mathrm{RI}$ in fetal descending aorta $(\mathrm{R}=-0.45, \mathrm{p}$ $=0.002)$, rather than umbilical artery $(\mathrm{R}=-0.34, \mathrm{p}=$ 0.02) correlated with deterioration of CTG stress test scores in the study groups. There was no correlation between RI and CTG score in both vessels $\left(\mathrm{Rc}_{\text {Aorta }}=-0.29\right.$; $\mathrm{p}=0.053 ; \mathrm{Rc}_{\text {Umbilical artery }}=-0.21, \mathrm{p}=0.17$ for the control group). A significant correlation existed in the $\mathrm{S} / \mathrm{D}$ ratios of aorta $(\mathrm{R}=-0.43, \mathrm{p}=0.004)$ and umbilical artery $(\mathrm{R}=$ $-0.33, p=0.03)$ with deterioration of CTG stress test score in the pre-eclamptic group.

Resistance index of $>80 \%$ in fetal descending aorta and late FHR decelerations were obtained in 52 of the 53 patients $(98 \%)$, whereas only 31 of $53(58 \%)$ patients had RI of $>80 \%$ in the umbilical artery together with late FHR decelerations. However, of the 53 patients, 11 (21\%) had RI of $<70 \%$ in umbilical artery although late FHR decelerations were detectable in 10 of these 11 patients (91\%). For the groups with pre-eclampsia alone or with HELLP syndrome, there was no correlation between the $\mathrm{RI}$ or $\mathrm{S} / \mathrm{D}$ ratio in the fetal descending aorta or umbilical artery and base excess. There was no correlation between $\mathrm{RI}$ or $\mathrm{S} / \mathrm{D}$ ratio of the aorta/umbilical artery and $\mathrm{pH}$ value, $\mathrm{pO}_{2}$ and Apgar Score after 1, 5 and 10 minutes ( $\left.\mathrm{p}>0.05\right)$ in patients with HELLP syndrome and controls. However, there was a significant increase in RI and $\mathrm{S} / \mathrm{D}$ ratios between descending aorta $\left(\mathrm{RI}_{\mathrm{p}}: \mathrm{R}=0.67 \mathrm{p}=0.0001\right.$; $\mathrm{RI}_{\text {Hellp }}: \mathrm{R}=0.84 \mathrm{p}=0.002 ; \mathrm{S} / \mathrm{D}_{\mathrm{p}}: \mathrm{R}=0.65 \mathrm{p}=0.0001$; $\left.\mathrm{S} / \mathrm{D}_{\text {Hellp }}: \mathrm{R}=0.87 \mathrm{p}=0.006\right)$ and umbilical artery $\left(\mathrm{RI}_{\mathrm{c}}: \mathrm{R}\right.$ $\left.=0.44 \mathrm{p}=0.003 ; \mathrm{S} / \mathrm{D}_{\mathrm{c}}: \mathrm{R}=0.46 \mathrm{p}=0.002\right)$ in both pre-eclamptic patients with and without HELLP syndrome.

\section{DISCUSSION}

Pre-eclampsia is associated with inadequate invasion of trophoblast leading to placental ischemia due to insufficiently dilated uterine spiral arteries [1]. This leads to hypertension, involving multiple organs. Treatment requires premature termination of pregnancy, either by caesarean section or vaginal delivery if cervical conditions are optimal. Many studies have associated preeclampsia with increased perinatal $(25 \%)$ and maternal (3\% - 5\%) morbidity and mortality [10-13], decreased neonatal birth weights and higher incidence of premature delivery $[12,14,15]$. The low birth rates recorded in our study for pre-eclamptic patients with or without HELLP syndrome are thus in agreement with previous reports $12,14,15]$. In this study, IUGR was associated with a decrease in end-diastolic flow velocities in the descend- 
ing aorta before changes in umbilical artery were detected. This decrease correlated with deterioration of CTG stress test score. Frequency of late FHR decelerations negatively correlated with an increase in RI and S/D ratio of the descending aorta rather than of umbilical artery. An increase in the RI and S/D ratio of the descending aorta negatively correlated with Base excess. No correlation was found between RI and S/D ratio of descending aorta, umbilical artery, $\mathrm{pH}$ and Apgar Scores. These results confirm that Doppler measurements of fetal descending aorta can give early warning of fetal boderline oxygenation. Although ductus venous, an index vessel for cardiac insufficiency is frequently used nowadays to monitor fetal distress, there is evidence that IUGR infants with severe changes of fetal blood in utero had impaired postnatal development of neurological $[16,17]$ and intellectual function [18]. These observations suggest that it may be advantageous to deliver IUGR fetuses before advent of venous flow impairment and deterioration of fetal heart rate [19]. According to Illanes and Soothill [20], delivery of a fetus that is well but a little less mature is likely to be better than one who is older but sick. Thus, management approaches that wait for fetal coma and renal failure as indicated by flat CTGs and severe oligohydramnios to decide time of delivery may not be appropriate. In one study, Brodszki et al. [21] reported that 23 adolescents with history of IUGR and abnormal fetal aortic bloodflow $(n=23)$ due to placental insufficiency had impaired vascular growth comprising of smaller aortic dimensions and higher resting heart rates, suggesting that fetal descending aorta may play a critical role in pre- and postnatal vascular development. According to Mandruzzato et al. [22] fetal descending aorta is suitable for blood flow velocity measurements because it provides 1) a straight course with good visualization from thoracic to abdominal part 2) great reliability and reproducibility of sample volume and angle estimation and 3) a likelihood that aortic thoracic blood flow velocity waveform reflects the hemodynamic state of a large portion of the fetal circulation (including placental perfusion, peripheral perfusion, and cardiac output). We used in addition to umbilical artery, a combination of Doppler measurements in fetal descending aorta and CTG stress test in order to secure delivery before onset of cardiac insufficiency that would have been detected by taking Doppler measurements of the ductus venous.

\section{CONCLUSION}

Although a number of studies have predominantly used ductus venous and umbilical artery as indices of fetal distress, data presented in this report demonstrate that Doppler measurements in the fetal descending aorta provide additional diagnostic value in detecting fetuses at risk for IUGR in pre-eclamptic pregnancies with or without HELLP syndrome.

\section{REFERENCES}

[1] Kang, A. and Struben, H. (2008) Pre-eclampsia screening in first and second trimester. Therapeutische Umschau, 65, 663-666. doi:10.1024/0040-5930.65.11.663

[2] Beucher, G., Simonet, T. and Dreyfus, M. (2008) Management of HELLP syndrome. Gynecology Obstetrics Fertility, 36, 1175-1190.

[3] Bush, K.D., O'Brien J.M., and Barton, J.R. (2001) The utility of umbilical artery Doppler investigation in women with the HELLP (hemolysis, elevated liver enzymes and low platelets) syndrome. American Journal of Obstetrics \& Gynecology, 184, 1087-1089. doi:10.1067/mob.2001.114506

[4] Baschat, A.A., Gembruch, U., Weiner, C.P. and Harman, C.R. (2003) Qualitative venous Doppler waveform analysis improves prediction of critical perinatal outcomes in premature growth-restricted fetuses. Ultrasound in $\mathrm{Ob}$ stetrics \& Gynecology, 22, 240-245. doi:10.1002/uog. 149

[5] Sterne, G., Shields, L.E. and Dubinsky, T.J. (2001) Abnormal fetal cerebral and umbilical Doppler measurements in fetuses with intrauterine growth restriction predicts the severity of perinatal morbidity. Journal of Clinical Ultrasound, 29, 146-151. doi:10.1002/1097-0096(200103/04)29:3<146::AID-JCU1 $014>3.0 . \mathrm{CO} ; 2-\mathrm{I}$

[6] Johnson, P., Stojikovic, T. and Sarkar, P. (2001) Middle cerebral artery Doppler in severe intrauterine growth restriction. Ultrasound in Obstetrics \& Gynecology, 17, 416-420. doi:10.1046/j.1469-0705.2001.00404.x

[7] Muller, T., Nanan, R., Rehn, M., Krieten, P. and Dietl, J. (2002) Arterial and ductus venosus Doppler in fetuses with absent or reverse end-diastolic flow in the umbilical artery: Correlation with short-term perinatal outcome. Acta Obstetricia et Gynecologica Scandinavica, 81, 860866. doi:10.1034/j.1600-0412.2002.810911.x

[8] Bilardo, C.M., Wolf, H., Stigter, R.H., Ville, Y., Baez, E., Visser, G.H.A. and Hecher, K. (2004) Relationship between monitoring parameters and perinatal outcome in severe, early intrauterine growth restriction. Ultrasound in Obstetrics \& Gynecology, 23, 119-125.

[9] Hohenauer, L. (1980) Intrauterine wachstumskurven fuer den deutschen sprachraum. Z Geburtsh. u . Perinat, 184, 167-179.

[10] Vigil De-Gracia, P. (2009) Maternal deaths due to eclampsia and HELLP syndrome. International Journal of Gynecology \& Obstetrics, 104, 90-94. doi:10.1016/j.ijgo.2008.09.014

[11] Sibai, B.M., Ramadan, M.K., Usta, I., Salama, M., Mercer, B.M. and Friedman, S.A. (1993) Maternal morbidity and mortality in 442 pregnancies with hemolysis, elevated liver enzymes, and low platelets (HELLP syndrome). American Journal of Obstetrics \& Gynecology, 169, 1000-1006. 
[12] Martin, J.N. Jr, Perry, K.G. Jr, Miles, J.F. Jr, Blake, P.G., Magann, E.F., Roberts, W.E. and Martin, R.W. (1993) The interrelationship of eclampsia, HELLP syndrome, and prematurity: Cofactors for significant maternal and perinatal risk. British Journal of Obstetrics and Gynaecology, 100, 1095-1100.

[13] Rath, W., Faridi, A. and Dudenhausen, J.W. (2000) HELLP syndrome. Journal of Perinatal Medicine, 28, 249-260. doi:10.1515/JPM.2000.033

[14] Joern, H. and Rath, W. (1998) Comparison of Doppler sonographic examinations of the umbilical and uterine arteries in high-risk pregnancies. Fetal Diagnosis and Therapy, 13, 150-153. doi:10.1159/000020827

[15] Joern, H., Funk, A. and Rath, W. (1999) Doppler sonographic findings for hypertension in pregnancy and HELLP syndrome. Journal of Perinatal Medicine, 27, 388-394. doi:10.1515/JPM.1999.053

[16] Ley, D., Laurin, J., Bjerre, I. and Marsal, K. (1996) Abnormal fetal aortic velocity waveform and minor neurological dysfunction at 7 years of age. Ultrasound in $\mathrm{Ob}$ stetrics \& Gynecology, 8, 152-159. doi:10.1046/j.1469-0705.1996.08030152.x

[17] Fouron, J.C., Gosselin, J., Amiel-Tison, C., Infante-Ri- vard, C., Fouron, C., Skoll, A. and Veilleux, A. (2001) Correlation between prenatal velocity waveforms in the aortic isthmus and neurodevelopmental outcome between the ages of 2 and 4 years. American Journal of Obstetrics \& Gynecology, 184, 630-636. doi:10.1067/mob.2001.110696

[18] Ley, D., Tideman, E., Laurin, J., Bierre, I. and Marsal, K. (1996) Abnormal fetal aortic velocity waveform and intellectual function at 7 years of age. Ultrasound in $\mathrm{Ob}$ stetrics \& Gynecology, 8, 160-165. doi:10.1046/j.1469-0705.1996.08030160.x

[19] Marsal, K. (2002) Intrauterine growth restriction. Current Opinion in Obstetrics and Gynecology, 14, 127-135.

[20] Illanes, S. and Soothill, P. (2004) Management of fetal growth restriction. Seminars in Neonatology, 9, 395-401.

[21] Brodszki, J., Lanne, T., Marsal, K. and Ley, D. (2005) Impaired vascular growth in late adolescence after intrauterine growth restriction. Circulation, 111, 2623-2628. doi:10.1161/CIRCULATIONAHA.104.490326

[22] Mandruzzato, G.P., Meir, Y.J., Maso, G., Conoscenti, G. and Rustico, M.A. (2003) Monitoring the IUGR fetus. Journal of Perinatal Medicine, 31, 399-407. doi:10.1515/JPM.2003.062 